\title{
Study on Prevalence of Fascioliasis in Ruminants in Dasht Room County in Spring and Summer of 2013
}

\author{
Moshfe Abdolali ${ }^{1}$, Rezaei Nasrabad Seyed Abbas ${ }^{2}$, Cheraghzadeh Seyed Reza ${ }^{1}$, Arefkhah Nasir ${ }^{3}$, \\ Zare Khafri Roohollah', Moein Masood ${ }^{2}$, Parhizgari Najmeh ${ }^{2}$, Jamshidi Ali ${ }^{3, *}$ \\ ${ }^{1}$ Cellular and Molecular Research Center, Yasuj University of Medical Sciences, Yasuj, Iran \\ ${ }^{2}$ Student Research Committee, Yasuj of University of Medical Sciences, Yasuj, Iran \\ ${ }^{3}$ Department of Parasitology and Mycology, Yasuj University of Medical Sciences, Yasuj, Iran
}

\section{Email address:}

a.jamshidi@zaums.ac.ir (Jamshidi A.), jamshidiali91@yahoo.com (Jamshidi A.)

${ }^{*}$ Corresponding author

\section{To cite this article:}

Moshfe Abdolali, Rezaei Nasrabad Seyed Abbas, Cheraghzadeh Seyed Reza, Arefkhah Nasir, Zare Khafri Roohollah, Moein Masood, Parhizgari Najmeh, Jamshidi Ali. Study on Prevalence of Fascioliasis in Ruminants in Dasht Room County in Spring and Summer of 2013. Animal and Veterinary Sciences. Vol. 4, No. 2, 2016, pp. 15-18. doi: 10.11648/j.avs.20160402.11

Received: January 14, 2016; Accepted: January 25, 2016; Published: March 12, 2016

\begin{abstract}
Fasciola spp is one of the liver bile ducts and gallbladder Trematodes in Ruminants. In the life cycle of the worm, snails are intermediate hosts and parasitic infection is happened by eating aquatic vegetables contaminated with Metacercaria. Humans also can be infected with this worm. Thus, Finding the contaminated villages where high infection in animals is reported, can help to control diseases. The aim of this study is to investigate the prevalence of Fascioliasis in Ruminants in 2013 in Dasht Room area, a rural district in Yasuj prevalence. This cross - sectional study, a total of 600 stool samples from Ruminants, including sheep, goat and cattle were collected from six villages in Dasht Room region. The stool samples were transported to the Parasitology laboratory and tested by standard Acid - Ether precipitation method (Thelman method). Sediments were studied with an optical microscope at magnifications of $\times 10.174$ out of 600 stool samples $(29 \%)$ were positive for Fasciola spp eggs, including 63 sheep (26/03\%), 40 goats (23/3\%) and 71 cattle (37/9\%), respectively. Significant differences between the infection rates of live stocks were not observed in spring and summer season. The most contamination was observed in cattle and the least in goat. Statistically significant difference was observed between them in summer season ( $\mathrm{P}<0 / 05)$. Considering to high contamination in the present study $(29 \%)$, Dasht Room County is a high risk area for Fasciolosis in Ruminants.
\end{abstract}

Keywords: Fascioliasis, Ruminants, Iran

\section{Introduction}

Liver flukes (Fasciola hepatica and Fasciola gigantica; Trematoda: Fasciolidae) are flatworm helminths which cause the disease Fasciolosis in Ruminants and humans [1]. Fasciolosis in important food born and water born parasitic zoonosis caused by liver fluke of the genus Fasciola [2], the Fasciola hepatica and Fasciola gigantica, are cosmopolitan in distribution, with high frequency in tropical area [3]. Fasciola spp. may reach the size of (25-30) $\mathrm{mm}$ in length and $(8-15) \mathrm{mm}$ width. It has leaf shaped Structure [4]. Fasciola spp has an interior and posterior sucker for attachment to host body [5]. Fasciola spp completed its entire life cycle in two host cattle, a definitive host, and the snail, an intermediate host, while the human is an accidental host, which causes disease mostly in ruminants, especially in cattle, buffaloes, sheep and goats. It may however affect human. These parasites inhabit the hepatobiliary system of the effected animal and rarely can be found in ectopic sites within the host body such as: lungs, diaphragm, intestinal wall, kidneys, and subcutaneous tissue can occur. Once the parasites eggs are ingested by the cattle by the occasional drinking or grazing, and then the parasites migrate through the liver parenchyma to reach the bile duct. The diagnosis of fasciolosis in ruminant caused by Fasciola spp. has been made solely by the detection of Fasciola eggs in the faces of infected animal [1, 4, 6-10]. The worldwide losses in animal productivity due to fasciolosis were estimated as US \$200 million per annum to rural agricultural communities and commercial producers with over 600 million animals infected. In developed counties, the incidence of Fasciola hepatica and Fasciola gigantica can reach up to $77 \%$. In 
tropical countries, fasciolosis is considered the single most important helminthes infection of cattle [11-13], with reported prevalence of 30-90\%. In domestic ruminants, adverse effects of acute or chronic fasciolosis include decreased meat and milk production, decreased fertility, and increased veterinary costs [14]. Fasciolosis is one of the big and most important worldwide problems mainly due to mortality of animals, cost of diagnosis, and treatment of condemned liver and it reduces milk and meat production $[15,16]$, fertility disorder, and drug resistance against fasciolosis [17]. Fasciolosis is estimated to be responsible for the annual loss of thousands of dollars in the Iranian agricultural industries. In Iran, fasciolosis in domestic ruminants is mainly caused by $F$. hepatica; however, the occurrence of $F$. gigantica has also been reported from different parts of the country [18]. The aim of this study is to investigate the prevalence of Fasciola hepatica and Fasciola gigantica infection in ruminants in 2013 in Dasht Room area, a rural district in Yasuj (Yasuj is a city in and the capital of Kohgiluye and Boyer-Ahmad Province, Iran. At the 2006 census, its population was 96,786, in 20,297 families. Yasuj is an industrial city in the Zagros Mountains of southwestern Iran. The term "Yasuj" is also used to refer to the entire region).

\section{Materials and Methods}

This cross - sectional study, a total of 600 stool samples from three types of animals including sheep, goat and cattle were collected from six villages (Amir Abad, Hossein Abad, Jahan Abad, Talkhdan, Tangari, Mansoor Abad) in Dasht Room region in spring and summer 2013(May \&August). The stool samples were transported to the laboratory and tested by standard Acid - ether precipitation method (Thelman method). Sediments were studied with an optical microscope at magnifications of $\times 10$. Data collected on the application EPI 2000 entered using the chi-square test (Chisquare) were analyzed. In This test, the chance of infection (Odds Ratio), Chi-square and P-value was evaluated and the amount of contamination in rural areas Dasht Room to separate species Fasciola spp, the seasonal pollution, and conflicts with the statistical comparison is kind of trap.

\section{Results and Discussion}

174 out of 600 stool samples (29\%) were positive for Fasciola spp eggs, including 63 sheep (26/03\%), 40 goats $(23 / 3 \%)$ and 71 cattle $(37 / 9 \%)$, respectively. Significant differences between the infection rates of ruminants were not observed in spring and summer seasions. The most infection was observed in Tangari and the least in Mansoor Abad villages with statistically significant differences $(\mathrm{P}<0 / 05)$. The most contamination was observed in cattle and the least in goat. Statistically significant difference was observed between them in summer seasion $(\mathrm{P}<0 / 05)$. The results of this study, by sampling season, type of ruminants and annual pollution listed in the tables below.

Table 1. The contamination of ruminants in the spring.

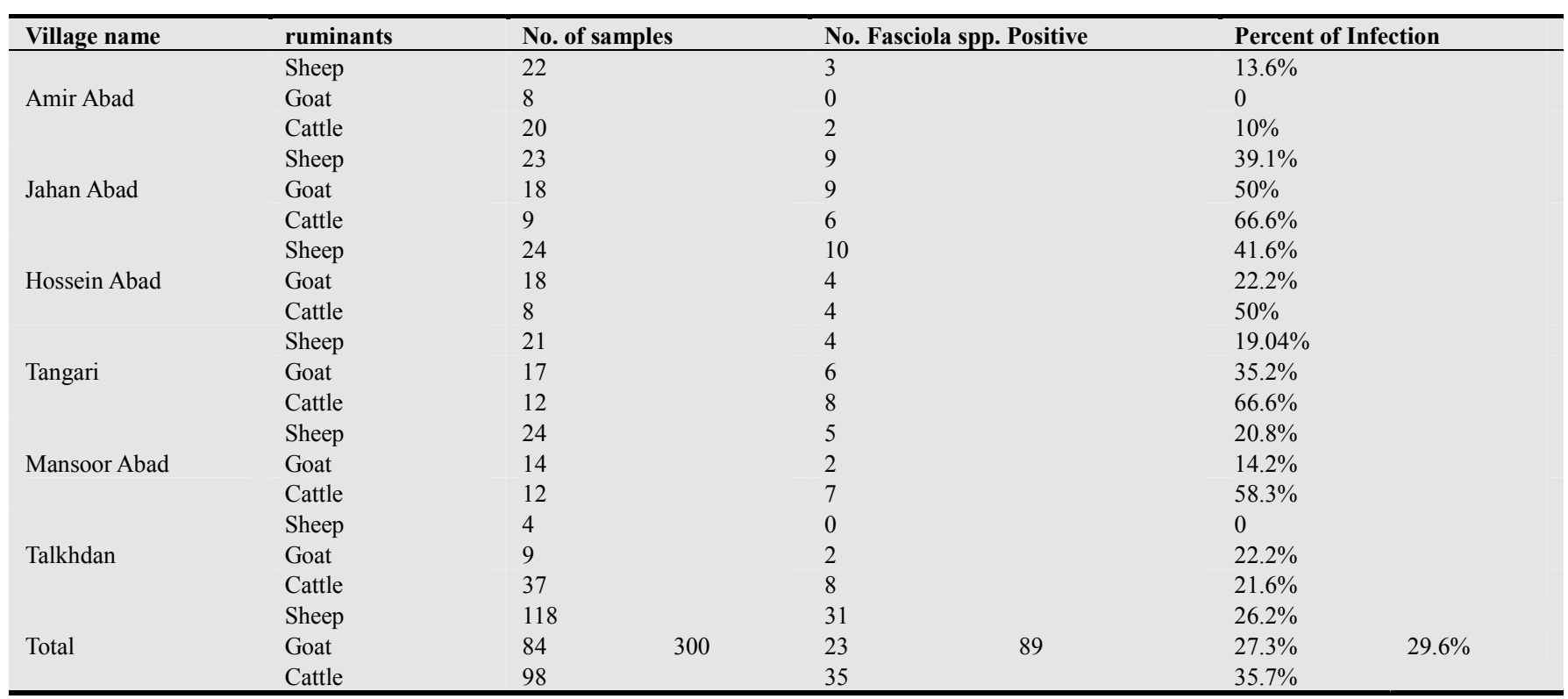

Table 2. The contamination of ruminants in the summer.

\begin{tabular}{|c|c|c|c|c|}
\hline Village name & Ruminants & No. of samples & No. Fasciola spp. Positive & Percent of Infection \\
\hline \multirow{3}{*}{ Amir Abad } & Sheep & 19 & 7 & $36.8 \%$ \\
\hline & Goat & 9 & 1 & $11.1 \%$ \\
\hline & Cattle & 22 & 12 & $54.5 \%$ \\
\hline \multirow{3}{*}{ Jahan Abad } & Sheep & 23 & 3 & $13.04 \%$ \\
\hline & Goat & 25 & 6 & $24 \%$ \\
\hline & Cattle & 2 & 1 & $50 \%$ \\
\hline \multirow{2}{*}{ Hossein Abad } & Sheep & 31 & 4 & $12.9 \%$ \\
\hline & Cattle & 13 & 3 & $23.07 \%$ \\
\hline
\end{tabular}




\begin{tabular}{|c|c|c|c|c|c|}
\hline \multirow{3}{*}{$\begin{array}{l}\text { Village name } \\
\text { Tangari }\end{array}$} & \multirow{2}{*}{$\begin{array}{l}\text { Ruminants } \\
\text { Sheep }\end{array}$} & No. of samples & \multicolumn{2}{|c|}{ No. Fasciola spp. Positive } & \multirow{2}{*}{$\begin{array}{l}\text { Percent of Infection } \\
39.1 \%\end{array}$} \\
\hline & & 23 & 9 & & \\
\hline & Goat & 16 & 7 & & $43.75 \%$ \\
\hline & Cattle & 11 & 4 & & $36.3 \%$ \\
\hline \multirow{3}{*}{ Mansoor Abad } & Sheep & 10 & 2 & & $20 \%$ \\
\hline & Goat & 19 & 1 & & $5.2 \%$ \\
\hline & Cattle & 21 & 2 & & $9.5 \%$ \\
\hline \multirow{3}{*}{ Talkhdan } & Sheep & 18 & 7 & & $38.8 \%$ \\
\hline & Goat & 12 & 1 & & $8.3 \%$ \\
\hline & Cattle & 20 & 14 & & $70 \%$ \\
\hline \multirow{3}{*}{ Total } & Sheep & 124 & 32 & $25.8 \%$ & \\
\hline & Goat & 300 & 17 & $19.5 \%$ & $28.3 \%$ \\
\hline & Cattle & 89 & 36 & $40.4 \%$ & \\
\hline
\end{tabular}

Table 3. The contamination of ruminants in the 2013 (spring and summer).

\begin{tabular}{|c|c|c|c|c|c|c|c|}
\hline \multicolumn{2}{|c|}{ Village name } & Ruminants & \multicolumn{2}{|c|}{ No. of samples } & \multicolumn{2}{|c|}{ No. Fasciola spp. Positive } & Percent of Infection \\
\hline \multirow{3}{*}{\multicolumn{2}{|c|}{ Amir Abad }} & Sheep & 41 & & 10 & & $24.3 \%$ \\
\hline & & Goat & 17 & & 1 & & $5.8 \%$ \\
\hline & & Cattle & 42 & & 14 & & $33.3 \%$ \\
\hline \multirow{3}{*}{\multicolumn{2}{|c|}{ Jahan Abad }} & Sheep & 46 & & 12 & & $26.08 \%$ \\
\hline & & Goat & 43 & & 15 & & $34.8 \%$ \\
\hline & & Cattle & 11 & & 7 & & $63.6 \%$ \\
\hline \multirow{2}{*}{\multicolumn{2}{|c|}{ Hossein Abad }} & Sheep & 55 & & 14 & & $25.4 \%$ \\
\hline & & Cattle & 21 & & 7 & & $33.3 \%$ \\
\hline \multirow{3}{*}{\multicolumn{2}{|c|}{ Tangari }} & Sheep & 44 & & 13 & & $29.5 \%$ \\
\hline & & Goat & 33 & & 13 & & $39.3 \%$ \\
\hline & & Cattle & 23 & & 12 & & $52.1 \%$ \\
\hline \multirow{3}{*}{\multicolumn{2}{|c|}{ Mansoor Abad }} & Sheep & 34 & & 7 & & $20.5 \%$ \\
\hline & & Goat & 33 & & 3 & & $9.09 \%$ \\
\hline & & Cattle & 33 & & 9 & & $27.2 \%$ \\
\hline \multirow{2}{*}{\multicolumn{2}{|c|}{ Talkhdan }} & Goat & 21 & & 3 & & $14.2 \%$ \\
\hline & & Cattle & 57 & & 22 & & $38.5 \%$ \\
\hline \multirow{3}{*}{ Total } & Sheep & 242 & & 63 & & $26.03 \%$ & \\
\hline & Goat & 171 & 600 & 40 & 174 & $23.3 \%$ & $29 \%$ \\
\hline & Cattle & 187 & & 71 & & $37.9 \%$ & \\
\hline
\end{tabular}

Compared with previous studies by "Moshfe et al, 2003" in Yasuj's Slaughterhouse (the prevalence of Fasciola hepatica was investigated and it was concluded that 27490 (14.4\%) domesticated animals out of the total number 190861 slaughtered domestic animals including sheep, goats and cattle has been infected by this parasite. Infection rate was $(9.26 \%)$. The prevalence rate of infection in sheep $(17.71 \%)$ was higher than the one in cattle $(16.71 \%)$ and in goats $(11.69 \%))$, this study showed high prevalence of Fasciola spp in ruminants, in Dasht Room area (29\%), due to high human population and proximity to the city of Yasuj and slaughterhouse is very important [19]. as a result of positive human serum against $F$. hepatica parasites in the area of Sarkari et al and the contamination of livestock in the study should Dasht Room one of the areas at risk and to prevent the high incidence knew Fasciolosis Awareness of the disease is serious action [20].

\section{Conclusion}

In general, previous studies and this study in Iran and other country it appears that the peak of infection is in the spring and summer growing season and abundance of aquatic plants and associated spring cattle and pasture, there is the issue of the season with this parasite struggle It is important [21]. Since most species of snails as an intermediate host in Iran live in fresh water and aquatic plants use water springs and ponds in the area with wild plants suitable place to live snails in the spring and summer Dasht Room provide [22]. According to previous studies mentioned results, Kohgiluyeh and BoyerAhmad as provincial livestock and ruminants susceptible to infection by Fasciola spp. The growth of the disease among cattle and human serum have been reported in the province and the city of Yasuj and Dasht Room area, the importance of preventing the common disease between humans and animals is necessary. Significant contamination of cattle ranchers in this study focus on the use of anti-parasitic drugs in this type of trap is needed because the financial losses will be even more significant. In this study it was found that Tangari village that is almost Dasht Room source of river pollution is more that people in these village officials require pollution prevention even in other villages. In this study there was no significant seasonal differences, though the prevalence in the present study compared with previous studies in the spring and summer transfer chance to show that a quarter of awareness of short duration can the cycle of life and the transition Fasciola spp did two seasons prevention.

\section{Acknowledgements}

This study was supported by Yasuj University of Medical Science. Study concept and design: Abdolali Moshfe, Seyed Abbas Rezaei Naserabad and Seyed Reza Cheraghzade. Acquisition of data: Seyed Abbas RezaeiNaserabad, Seyed 
Reza Cheraghzade, Nasir Arefkhah, Roohollah Zare Khafri, Masood Moein and Najmeh Parhizgari. Analysis and interpretation of data: Abdolali Moshfe, Seyed Abbas RezaeiNaserabad and Seyed Reza Cheraghzade. Drafting of the manuscript: Ali Jamshidi. Critical revision of the manuscript for important intellectual content: Abdolali Moshfe and Ali Jamshidi.

\section{References}

[1] T. P Elliott, "High prevalence of fasciolosis and evaluation of drug efficacy against Fasciola hepatica in dairy cattle in the Maffra and Bairnsdale districts of Gippsland, Victoria, Australia", Veterinary parasitology. 2015; 209(1-2): 117-24.

[2] S Mas-Coma," Fascioliasis and other plant-borne trematode zoonosis", International journal for parasitology. 2005; 35(11-12): 1255-78.

[3] T. W Spithill," Progress in development of liver fluke vaccines", Parasitology today. 1998; 14(6): 224-8.

[4] D Bozkov,"rules on the life cycle of trematodes in the ecosystem", Angewandte Parasitologie. 1980; 21(2): 91-4.

[5] J. W McGarry, "PCR-based differentiation of Fasciola spp (Trematoda: Fasciolidae), using primers based on RAPDderived sequences", Annals of tropical medicine and parasitology. 2007; 101(5): 415-21.

[6] S Ayaz, "Fasciola hepatica in some Buffaloes and cattle by PCR and microscopy", The Scientific World Journal. 2014; 2014: 462084.

[7] I Cruz-Mendoza, "Transmission dynamics of Fasciola hepatica in the Plateau Region of Mexico. Effect of weather and treatment of mammals under current farm management", Veterinary parasitology. 2011; 175(1-2): 73-9.

[8] H. H Garcia, "Zoonotic helminth infections of humans: echinococcosis, cysticercosis and fascioliasis", Current opinion in infectious diseases. 2007; 20(5): 489-94.

[9] L Marcos, "Risk factors for Fasciola hepatica infection in children: a case-control study", Transactions of the Royal Society of Tropical Medicine and Hygiene. 2006; 100(2): 15866.

[10] M. V Periago, "First phenotypic description of Fasciola hepatica/Fasciola gigantica intermediate forms from the human endemic area of the Nile Delta, Egypt. Infection, genetics and evolution", journal of molecular epidemiology and evolutionary genetics in infectious diseases. 2008; 8(1): 51-8.
[11] K Ashrafi, "Fascioliasis: a worldwide parasitic disease of importance in travel medicine", Travel medicine and infectious disease. 2014; $12(6 \mathrm{Pt}$ A): 636-49.

[12] M Mezo," The wild boar (Sus scrofa Linnaeus, 1758) as secondary reservoir of Fasciola hepatica in Galicia (NW Spain)", Veterinary parasitology. 2013; 198(3-4): 274-83.

[13] S. Y Cho, "A Case Of Human Fascioliasis In Korea", Kisaengch'unghak chapchi The Korean journal of parasitology. 1976; 14(2): 147-52.

[14] G Theodoropoulos, "Abattoir condemnation due to parasitic infections and its economic implications in the region of Trikala, Greece", Journal of veterinary medicine B, Infectious diseases and veterinary public health. 2002; 49(6): 281-4.

[15] A Olsen, "Prevalence, risk factors and spatial analysis of liver fluke infections in Danish cattle herds", Parasites \& vectors. 2015; 8: 160 .

[16] G. L Hickey, "The feasibility of testing whether Fasciola hepatica is associated with increased risk of verocytotoxin producing Escherichia coli $\mathrm{O} 157$ from an existing study protocol", Preventive veterinary medicine. 2015; 119(3-4): 97104.

[17] J Keiser, "Chemotherapy for major food-borne trematodes: a review", Expert opinion on pharmacotherapy. 2004; 5(8): 1711-26.

[18] A Imani-Baran, "Molecular study for detecting the prevalence of Fasciola gigantica in field-collected snails of Radix gedrosiana (Pulmonata: Lymnaeidae) in northwestern Iran", Veterinary parasitology. 2012; 189(2-4): 374-7.

[19] A. A Moshfe, "Prevalence of Fasciola Hepatica in Slaughtered livestock in Yasuj's Slaughterhouse", Armeghandanesh. 2003; 8(30): 26-33.

[20] R Shafiei, "Molecular and Morphological Characterization of Fasciola spp. Isolated from Different Host Species in a Newly Emerging Focus of Human Fascioliasis in Iran", Veterinary medicine international. 2014; 2014: 405740.

[21] K Khallaayoune, "Seasonal variations of Fasciola hepatica infection in goats in the area of Haouz (Morocco)", Annales de recherches veterinaires Annals of veterinary research. 1991; 22(2): 219-26.

[22] B Imani, "Survey of Population Changes and Cercarial Infection of Lymnaea spp Freshwater Snails. in Miyandoab Region, West Azarbaijan Province in 2010", journal of university Rafsanjan of medical science. 2014; 13(7): 596-81. 